\title{
ELECTROLYTE EQUILIBRIUM DURING MERCURIAL DIURESIS 1,2
}

\author{
By WILLIAM B. SCHWARTZ ${ }^{3}$ AND WILLIAM M. WALLACE \\ (From the Medical Services of the Peter Bent Brigham Hospital and the Children's Medical \\ Center and the Departments of Medicine and Pediatrics, Harvard Medical School, \\ Boston, Mass.)
}

(Submitted for publication May 23, 1951; accepted July 30, 1951)

\section{INTRODUCTION}

Earlier workers have shown that the amount of fixed cation contained in the extra urine voided during the course of mercurial diuresis corresponded to that contained in an equivalent amount of body fluid, while the quantity of chloride was greater than that which would be expected to be found in the fluid lost. This differential loss of chloride was shown to result in hypochloremic alkalosis. It was further observed that the administration of acidifying salts prevented the occurrence of alkalosis and at the same time enhanced diuresis $(1,2)$.

The observations reported in this communication indicate that the alteration in the concentration of chloride and bicarbonate in the serum that follows repeated diureses with a mercurial is usually accompanied by unresponsiveness to further administration of the drug. The various patterns of electrolyte loss observed during mercurial diuresis, their significance in relation to body composition, and their relation to certain clinical and physiologic problems will be discussed.

\section{METHODS AND CALCULATIONS}

Ten patients in congestive heart failure as the result of rheumatic or hypertensive heart disease were studied on the metabolism ward of the Peter Bent Brigham Hospital. All were chosen on the basis of their willingness and ability to cooperate in the collection of specimens and the consumption of a constant diet. Six were males

\footnotetext{
1 This investigation was supported by research grants from the National Heart Institute of the National Institutes of Health, U. S. Public Health Service, the Grant Foundation, Mead Johnson and Company, and Lakeside Laboratories, Inc.

2 Presented in abstract form at the 42nd Annual Meeting of the American Society for Clinical Investigation, Atlantic City, N. J., May 1, 1950.

8 Present address: New England Center Hospital and Tufts College Medical School, Boston, Mass.
}

and four were females. Control periods were obtained when the clinical situation allowed. In most instances, however, it was deemed necessary to begin therapy at once. Each patient was placed on a constant weighed diet that contained minimal sodium and approximated the usual ward diet with regard to nitrogen and caloric value. Every third day a duplicate diet was analyzed for sodium, chloride, potassium, and nitrogen. All food refused was saved for analysis and the intake figures corrected accordingly. Water intakes were kept as constant as possible.

The mercurial compound (Mercuhydrin) was administered intramuscularly in a standard dose of $2 \mathrm{cc}$. at the beginning of each day of treatment.

The urine was collected for 24-hour periods, with thymol in chloroform used as preservative. The feces were collected from eight of the ten patients and were pooled in four to six-day periods. Carmine was used to mark the beginning and end of each period. The urine and stools were analyzed for sodium, chloride, potassium, and nitrogen. In addition, titratable acidity, $\mathrm{pH}$, ammonia, and total phosphorus were determined in the urine.

Venous blood was drawn without stasis in oiled syringes at the beginning of each daily collection period while the patient was fasting. At the time of blood sampling the patient was weighed to the nearest 50 grams.

The methods used for determination of sodium, potassium, chloride, nitrogen, $\mathrm{pH}$, and carbon dioxide have been described in a previous paper from this laboratory (3). Urine titratable acidity was determined by the method of Henderson and Palmer (4) and ammonia was determined by the method of Folin (5).

Balance data were calculated as net intake, minus combined output in urine and stool. The quantity of substance in the pooled stool collections was divided by the number of days in the collection period to obtain the average figure for the daily stool output. No unusually large stools were passed by any of the subjects reported in this study and daily losses were assumed to be equal. Changes in the volume of the chloride space and shifts of sodium into and out of the intracellular fluid were calculated by methods previously described and used by various authors, (6-8). The form of the calculation and the factors used have been detailed in a previous paper from this laboratory (3). In calculation of the present data the changes in chloride space were calculated backward from the balance of chloride using the assumption that chloride was distributed through $20 \%$ of the body weight at the end of the period of diuresis. 


\section{RESULTS}

The ten patients with congestive heart failure were observed for a combined total of 22 periods during which Mercuhydrin was administered. The essential features with regard to the ratio of sodium to chloride $(\mathrm{Na} / \mathrm{Cl}$ ratio) of the negative balance, the potassium loss or absence thereof, and the development of unresponsiveness to the diuretic are summarized in Table I. A patient was considered to be unresponsive if he was still edematous and his weight did not change after administration of the diuretic. The data are too few to allow a categorical statement about the relationship of the character of the balance losses to the development of unresponsiveness but a certain grouping of patients appears possible. A review of therapy employed prior to the period of study with respect to diuretics, digitalis and salt restriction showed no apparent correlation with the urine $\mathrm{Na} / \mathrm{Cl}$ ratio during diuresis. Two of the patients (V.S., B. C.) responded to the diuretic by the loss of body fluid the composition of which was similar to that of extracellular fluid. In these, the $\mathrm{Na} / \mathrm{Cl}$ ratio of the negative balance was above unity; neither alkalosis nor negative potassium balance developed and the patients were continually responsive until approximately normal weight was reached. In eight of the patients the $\mathrm{Na} / \mathrm{Cl}$ ratio of the negative balance was less than 1 . In these subjects there was a fall in serum chloride and a rise in serum bicarbonate concentrations, often accompanied by a negative balance of potassium and a reduction in serum potassium concentration. In all but one (S. S.) of these patients unresponsiveness appeared. The administration of ammonium chloride in amounts sufficient to return the serum chloride and bicarbonate to normal in the refractory alkalotic patients also restored responsiveness in every instance.

Analytical data from four representative subjects (V. S., F. C., N. B., and S. S.) are presented in Tables II-V and Figures 1-6. Figures 1-4 show the daily values for the serum electrolytes, the course of the cumulative balance of electrolytes, the cumulative course of the change of body weight, and an estimate of the shifts of sodium and potassium between extracellular and intracellular fluid. The cumulative nitrogen balance is plotted as grams times 2.7 to indicate the degree of deviation of potassium and nitrogen from the theoretical losses that would occur if body tissue as a whole were being lost or gained (9). The ordinate indicating the cumulative weight loss is so chosen that one $\mathrm{kg}$. equals a value on the $\mathrm{mEq}$. ordinate equivalent to the mean calculated value for extracellular fluid sodium during the period of observation.

In the theoretical situation in which only extracellular fluid is being lost these two cumulative balances should coincide. Deviation of the two curves from each other indicates unmeasured losses through the skin, losses of intracellular fluid, or shifts of sodium into or out of the intracellular compartment. Minimal sweating occurred during these experiments so that losses of sodium through the skin were probably about 5 to $10 \mathrm{mEq}$./day $(10,11)$.

The calculated shifts of sodium between the ex-

TABLE I

Interrelationships of $\mathrm{Na} / \mathrm{Cl}$ ratio of balance to $K$ loss and unresponsiveness

\begin{tabular}{|c|c|c|c|c|c|c|c|}
\hline \multirow{3}{*}{ Subject } & \multirow{2}{*}{\multicolumn{3}{|c|}{$\frac{\mathrm{Na}}{\mathrm{Cl} \text { of balance }}$}} & \multicolumn{3}{|c|}{$\mathbf{K}$ loss } & \multirow{3}{*}{ Remarks } \\
\hline & & & & \multicolumn{3}{|c|}{ Diuretic period } & \\
\hline & 1 & 2 & 3 & 1 & 2 & 3 & \\
\hline $\begin{array}{l}\text { V.S. } \\
\text { B. C. } \\
\text { F. C. } \\
\text { N. B. } \\
\text { S. S. } \\
\text { J. C. } \\
\text { C. A } \\
\text { S. H. } \\
\text { J. B. } \\
\text { C. G. }\end{array}$ & $\begin{array}{r}1.21 \\
1.39 \\
.73 \\
.66 \\
.44 \\
.29 \\
.62 \\
.94 \\
.60 \\
.91\end{array}$ & $\begin{array}{r}1.33 \\
.51 \\
.50 \\
.57 \\
.78 \\
.90 \\
.57 \\
.61 \\
.68\end{array}$ & $\begin{array}{r}1.14 \\
.53 \\
.56\end{array}$ & $\begin{array}{l}0 \\
0 \\
+ \\
+ \\
+ \\
+ \\
+ \\
0 \\
0 \\
+ \\
0\end{array}$ & $\begin{array}{l}0 \\
+ \\
+ \\
+ \\
0 \\
0 \\
0 \\
0 \\
+ \\
0\end{array}$ & $\begin{array}{l}0 \\
+ \\
0\end{array}$ & $\begin{array}{l}\text { Continually responsive } \\
\text { Continually responsive } \\
\text { Refractory at the end of each period } \\
\text { Refractory at the end of each period } \\
\text { Continually responsive } \\
\text { Refractory at the end of each period } \\
\text { Refractory at the end of each period } \\
\text { Refractory at the end of each period } \\
\text { Refractory at the end of each period } \\
\text { Refractory at the end of each period }\end{array}$ \\
\hline
\end{tabular}




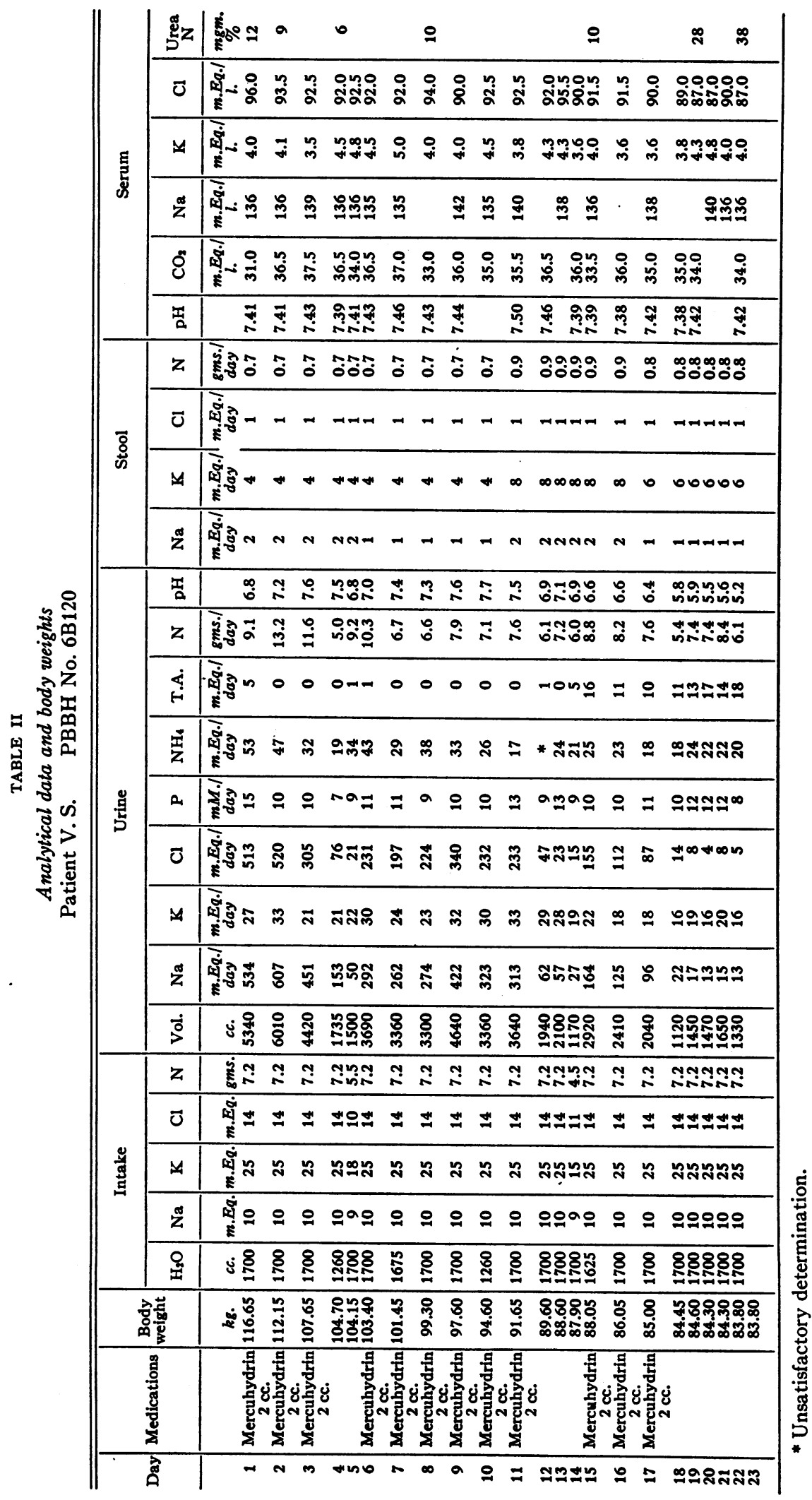




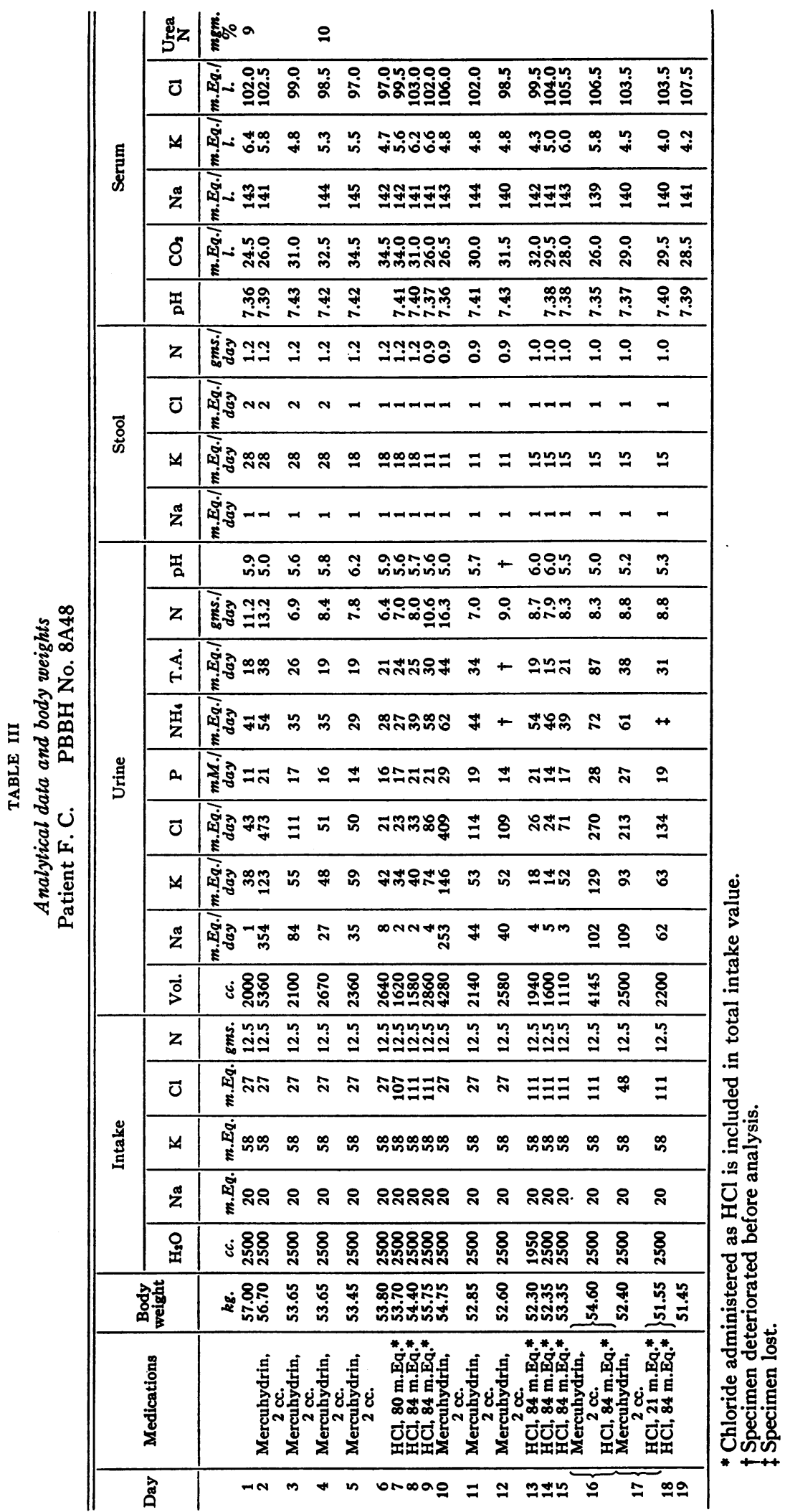




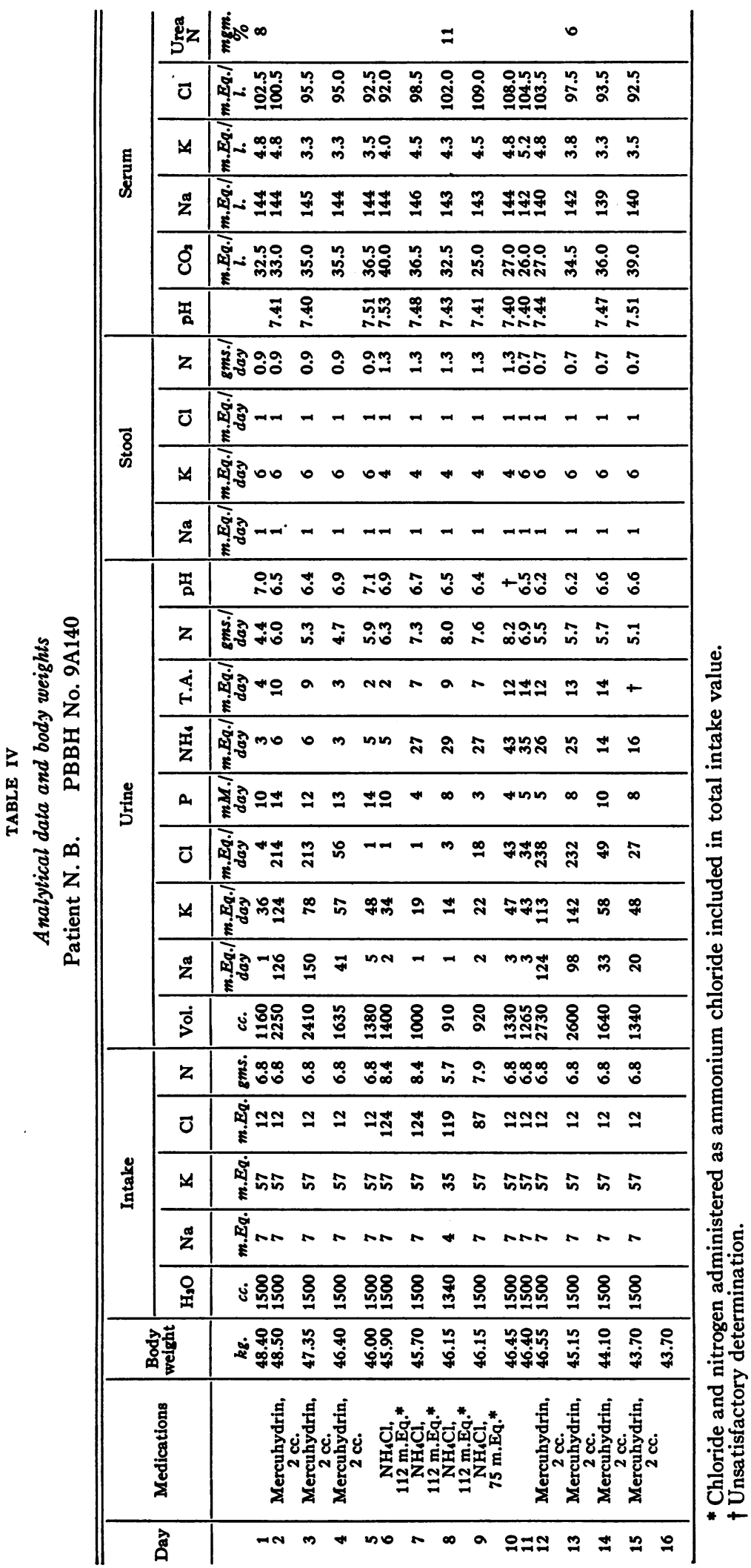




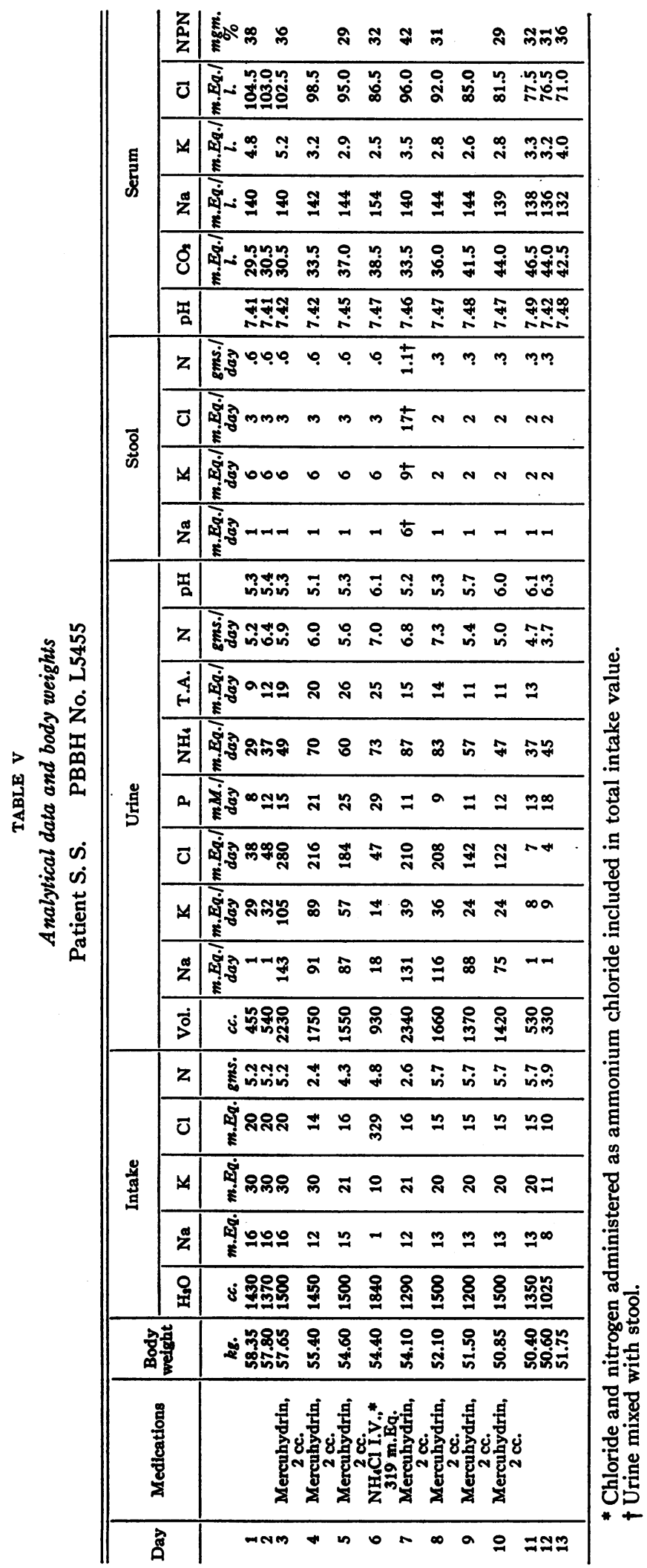


tra- and intracellular compartments, as well as the loss or gain of intracellular potassium, are indicated at the bottom of the chart. These intracellular balances are cumulative only for the period indicated. For example, in Figure 3, the shifts during the first four days are indicated at the end of the fourth day; the shift on day 11 is cumulative for days five through 11 , and not for the entire 11-day period.

Graphic presentation of the intracellular shifts has been made in terms of the percentage of estimated total extracellular fluid sodium on the day

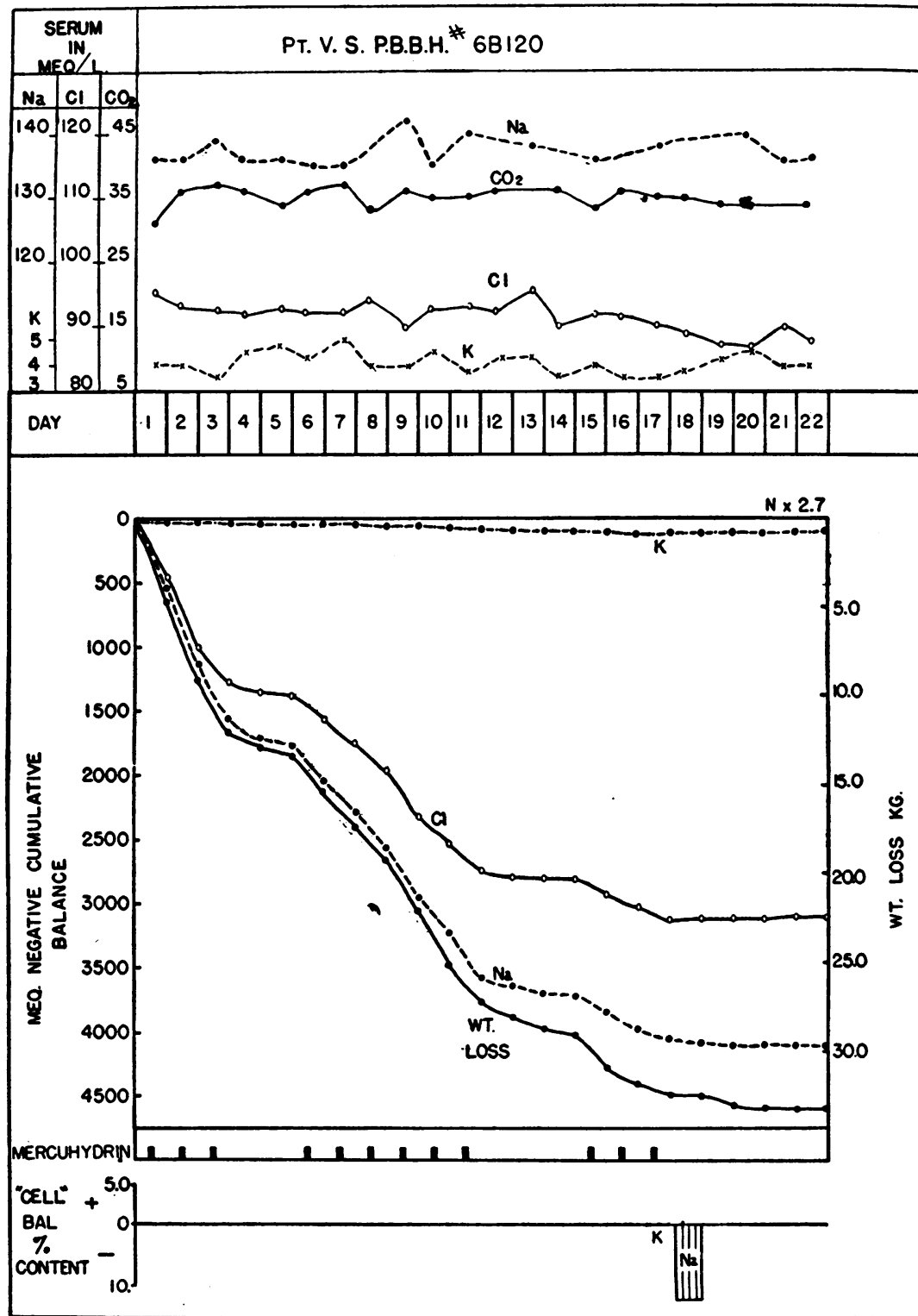

Fig. 1. Serum Electrolyte Concentrations, External and Internal Balances in Relation to Therapy for Patient V. S. (Table II) Showing Continued Response to the Diuretic without Progressive Changes in Serum CONCENTRATIONS

In this and the succeeding three charts the coordinate indicating weight loss is chosen to predict the theoretical sodium loss as calculated from mean extracellular fluid sodium concentration (see text). 


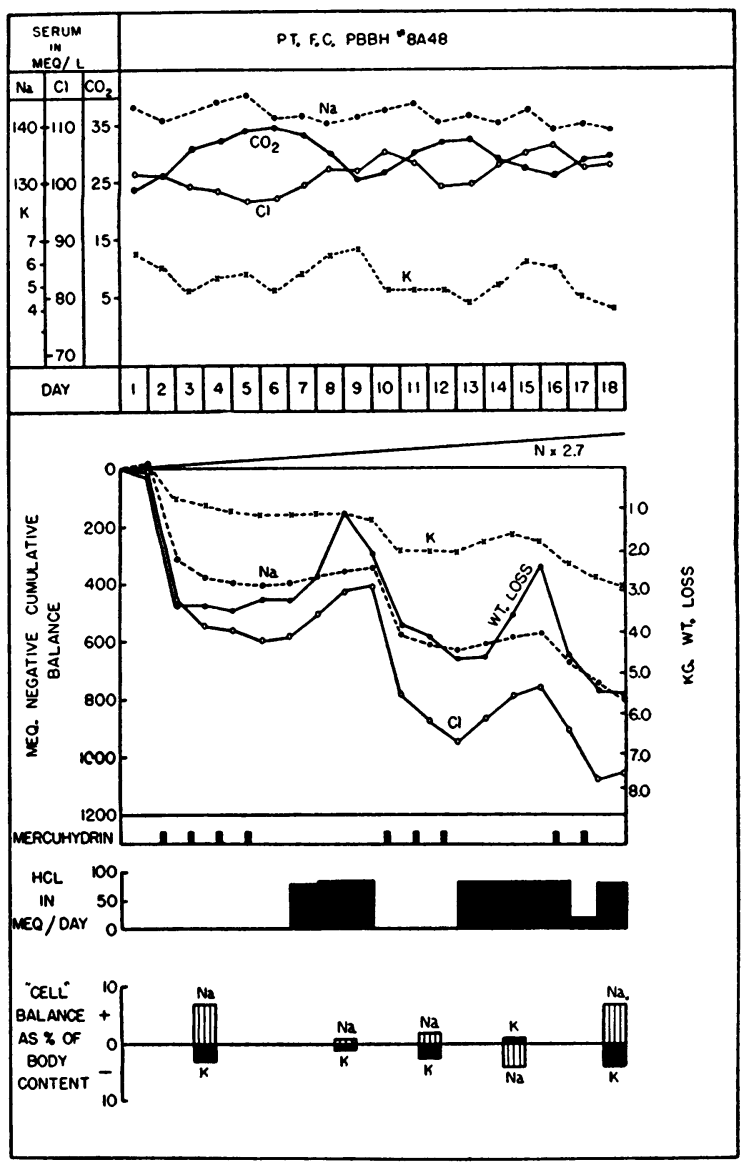

Fig. 2. Serum Electrolyte Concentrations, External and Internal Balances in Relation to Therapy for Patient F. C. (Table III) Showing Three Successive Episodes of Mercurial Diuresis Accompanied by Alkalosis and Unresponsiveness and DemONSTRATING THE RETURN OF RESPONSIVENESS With HyDROCHLORIC ACID AdMINISTRation

chosen for the calculation and the percentage of total estimated intracellular potassium in order to bring these calculated values into proper perspective with the total amounts involved. Total body potassium was estimated from the body weight at the end of the period of observation, based on the value $68 \mathrm{mEq} . / \mathrm{kg}$. given by Shohl (12).

The necessity for presentation in this way is obvious when the method of calculation is examined. It is evident that analytical errors in the determination of serum sodium and chloride concentrations can produce large changes in the apparent quantity of sodium shifting between cells and extracellular fluid. In the present study the analyses for serum sodium and chloride are as- sumed to carry a possible error of $\pm 2 \%$, the technique of the balance, an error of $\pm 5 \%$, and the determination of weight, an error of $\pm 1 \%$. When the analytical values are applied in the equations used, calculation of the summation of these possible errors ${ }^{3}$ indicates that at least $6 \%$ of the extracellular sodium must shift into or out of cells before the shifts can have even statistical significance.

${ }^{3}$ The equations used in calculation of the summation of errors were:

1. $(A \pm a) \pm(B \pm b)=A+B \pm \sqrt{a^{2}+b^{2}}$,

2. $(A \pm a) \times(B \pm b)=A B \pm \sqrt{(A B)^{2}+(B a)^{2}}$,

3. $(A \pm a)(B \pm b)(C \pm c)$ $=\mathrm{ABC} \pm \sqrt{(\mathrm{aBC})^{2}+(\mathrm{bAC})^{2}+(\mathrm{cAB})^{2}}$,

4. $\frac{B \pm b}{A \pm a}=\frac{B}{A} \pm \frac{1}{A} \sqrt{\left(\frac{B a}{A}\right)^{2}+b^{2}}$.

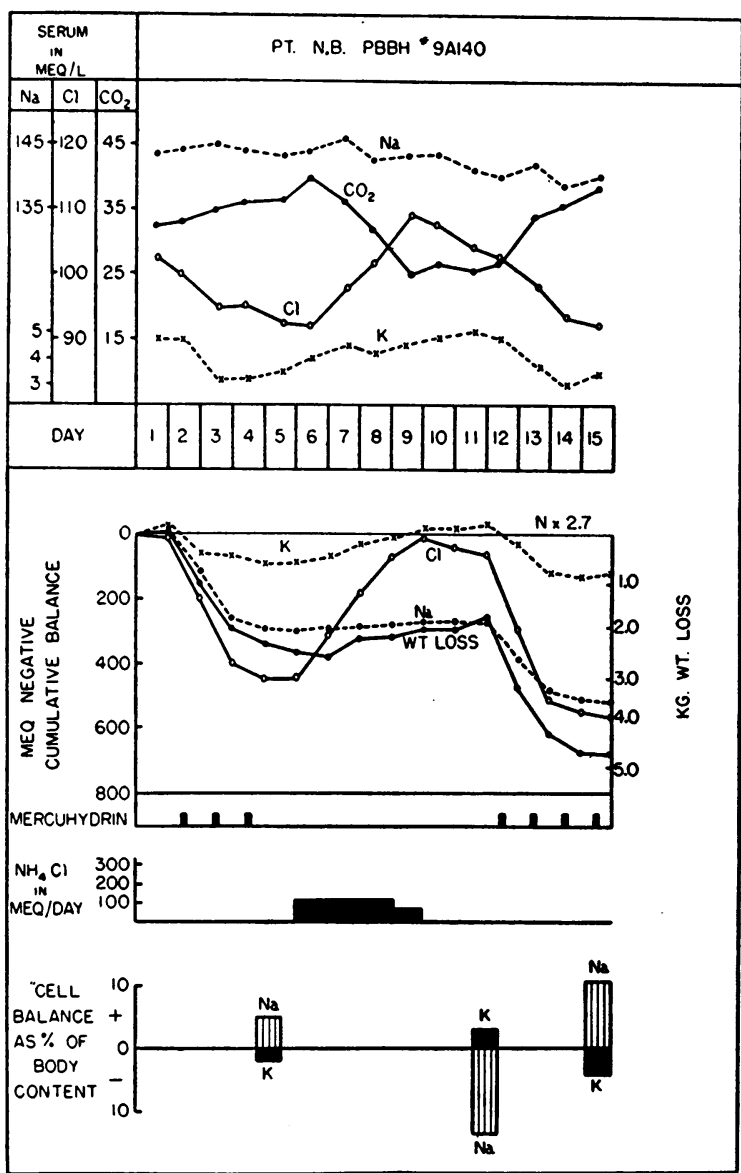

Fig. 3. Serum Electrolyte Concentrations, External and Internal Balances in Relation to Therapy for Patient N. B. (Table IV) Showing a Pattern Similar to that for Patient F. C. 
The data on a massively edematous patient ( $V$. S.), who lost $33 \mathrm{~kg}$. of weight during a 22 -day period of observation, are presented in Table II. Figure 1 is a graphic presentation of part of these data. Serum analyses showed an elevation of serum bicarbonate concentration and a reduction in chloride concentration prior to diuresis. On the first day of diuresis an additional elevation of the bicarbonate concentration occurred. After this initial rise, however, patient V. S. continued to diurese without progression of the serum changes. These variations from normal concentrations were not seen in the other patient (B. C.), whose diuresis was of the same type as that described in Figure 1.

The diuretic was administered at intervals throughout the period of study. At each interruption of treatment with mercury, loss of electrolyte and of body weight quickly stopped. Resumption of treatment resulted in renewed diuresis. At no time was the patient unresponsive. The negative balance of sodium was always greater than that of chloride and the ratio of the losses was approximately the same as the ratio of sodium to chloride in extracellular fluid. The course of the cumulative nitrogen and potassium balance indicated that intracellular fluid remained undisturbed. The curves for weight loss and sodium loss nearly coincided, a further indication of the extracellular nature of the fluid loss. The slight deviation of the two curves, as well as the indicated shift of sodium into cells, could well be accounted for by unmeasured losses. The $\mathrm{pH}$ of the urine remained between 6.4 and 7.7 during the course of the diuresis. No significant changes occurred in the daily total excretion of titratable acid or ammonia.

The data on two patients (F. C., N. B.), who at first responded to the administration of the diuretic but quickly became unresponsive, are given in Tables III and IV and are graphically shown in Figures 2 and 3 . In both of these patients the negative balance of chloride exceeded the negative balance of sodium. Hypochloremic alkalosis developed without change in serum sodium concentration. Unlike the subject (V. S.) previously described, a negative balance of potassium occurred in the initial phase of diuresis and the concentration of serum potassium decreased on the initial day. As serum chloride concentration fell and bicarbo-

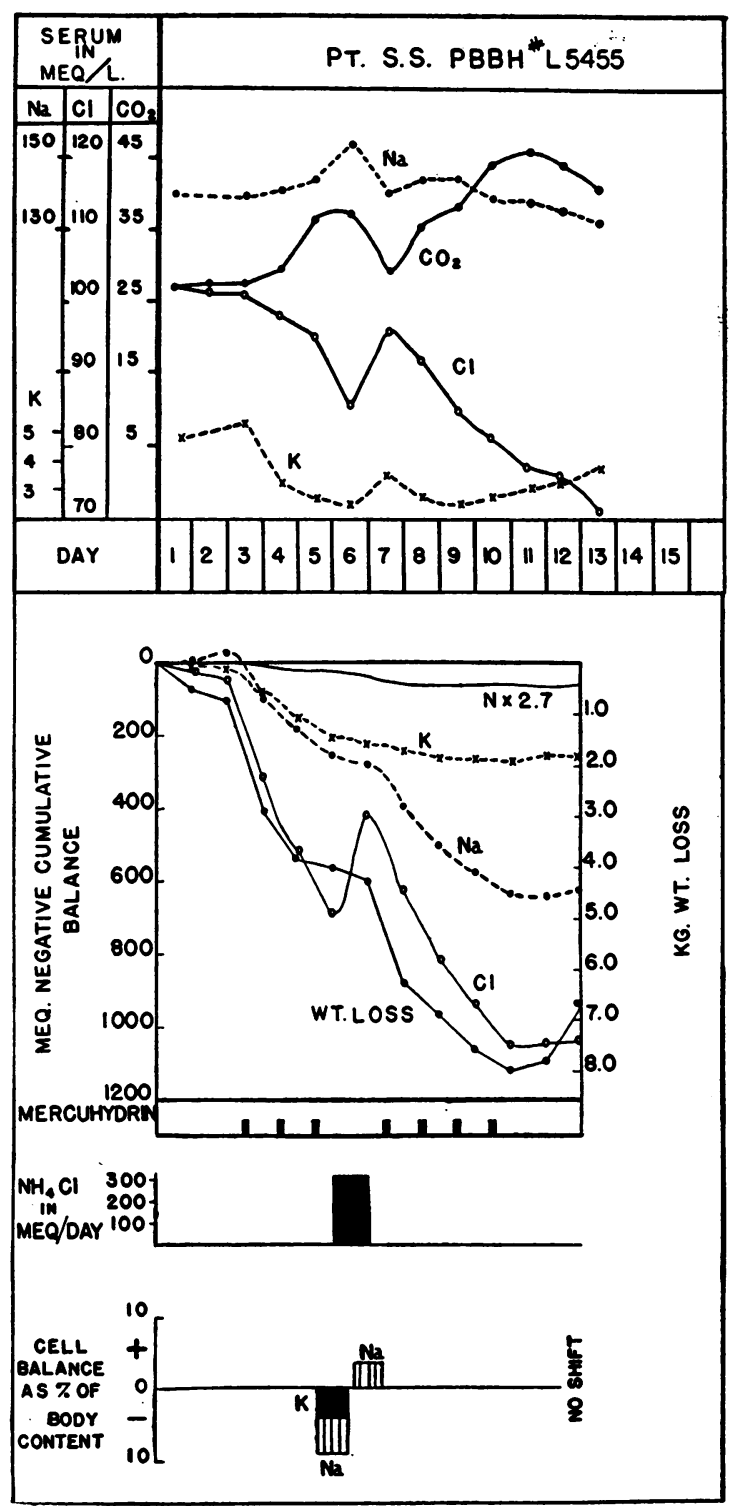

Fig. 4. Serum Electrolyte Concentrations, ExTERnal and Internal Balances in Relation to Therapy for Patient S. S. (Table V) Showing Continued Responsiveness to Therapy Despite Development of Hypochloremic Alkalosis

nate concentration rose both subjects became refractory to further administration of the diuretic.

The administration of ammonium chloride or hydrochloric acid returned the serum concentrations of bicarbonate and chloride to normal. Both subjects once again responded to treatment with mercury but further diuresis resulted in repetition of essentially the same cycle.

The potassium loss noted in the two patients 

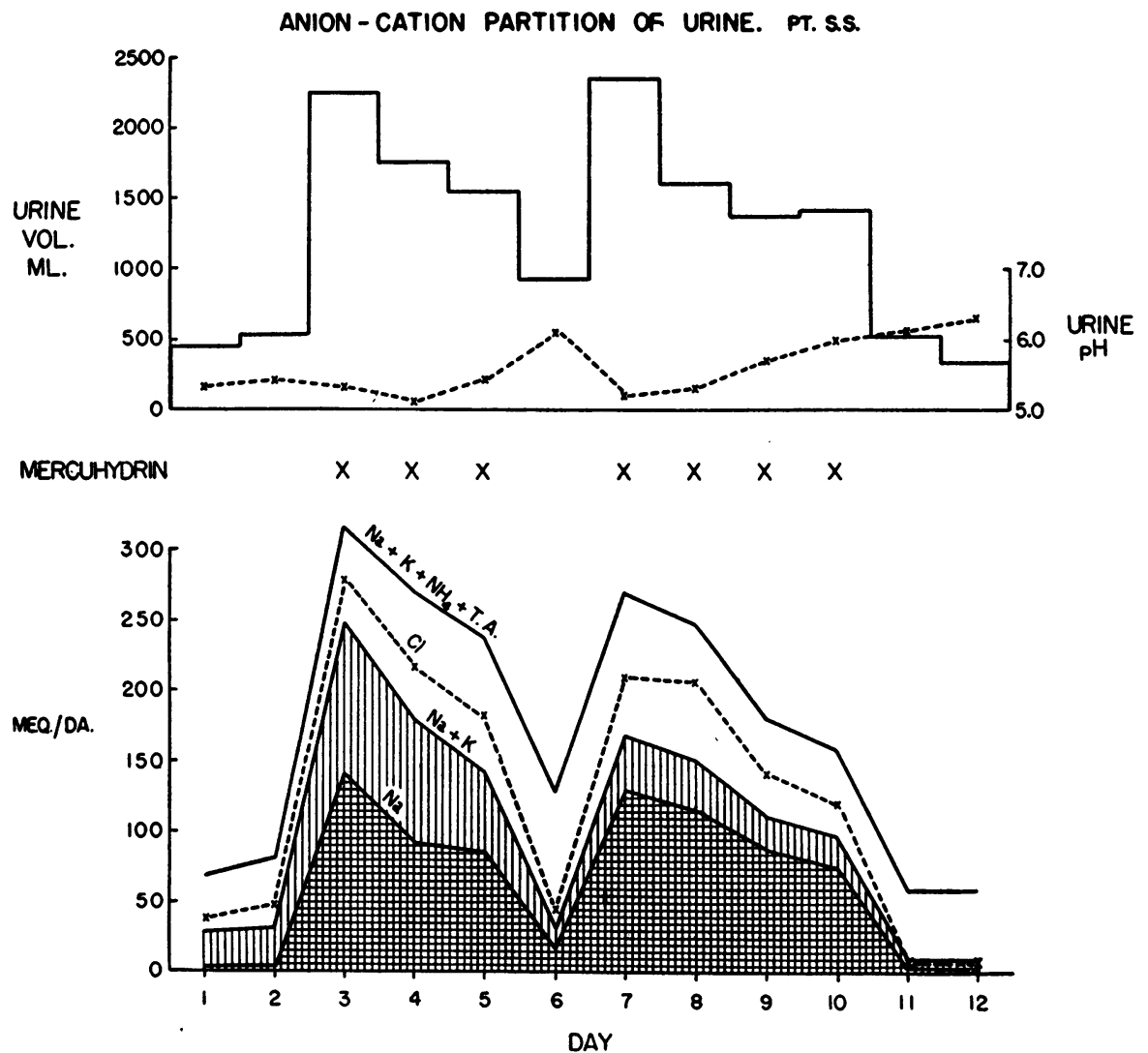

Fig. 5. Daily Urine Volume, Urine pH and the Anion-Cation Partition of the Urine during Two Diuretic Periods for S. S. (TAble V)

Note that chloride excretion is always greater than the sum of excretions of sodium and potassium.

described in Figures 2 and 3 did not invariably accompany the development of alkalosis. In three subjects (shown in Table I) alkalosis occurred without any loss of potassium. It will be noted, however, that during all four diuretic periods described for F. C. and N. B., potassium was lost in excess of nitrogen and in excess of the small amounts that would be expected from the simple loss of extracellular fluid. The physiologic significance of this loss is difficult to evaluate but may be assessed in terms of the percentage loss of estimated total body potassium. Patient N. B., at the end of the period of study, had lost approximately $6 \%$ of her estimated total body potassium. In her the potassium losses were repaired from a fixed intake during the period of chloride administration. In F. C., however, the potassium losses during each period of diuresis were additive and the net loss at the end of the experiment was more than
$10 \%$ of the estimated total body potassium, yet there were no clinical or electrocardiographic evidences of potassium deficiency and the serum potassium level was within normal limits.

Examination of the relation of the actual weight loss to theoretical weight loss calculated from sodium showed that intracellular fluid as well as extracellular fluid was lost. During each period of diuresis in both subjects the weight loss calculated from sodium was seen to be less than the observed weight loss, the difference roughly approximating the amount that might be calculated from the loss of potassium associated with the loss of intracellular water. The difficulties that arise from attempts to predict shifts in water by calculation from observed body weights and balance measurements for electrolytes have been stressed by Yannet and Darrow (13) and Elkinton and coworkers (8). For this reason no attempt was 
made to quantitatively assess the relationship of potassium loss to intracellular fluid loss. The inconsistencies that would be encountered are particularly evident in Figure 2, where it is seen that during the periods when hydrochloric acid was administered, increments in body weight occurred without simultaneous retention of either sodium or potassium. It may be postulated that changes of this nature are related to an "activation" of cellular cation, but they can probably be more reasonably explained as resulting from changes in dissociation of intracellular anion (phosphate) and a consequent increase in the number of osmotically active particles (14). The additional possibility that there is a primary disturbance in the excretion of water can not be ruled out. The degree of retention would be expected to produce only a slight change in tonicity, difficult to identify by measurements of serum sodium concentration.

The intracellular balances seen in Figures 2 and 3 show that during the development of alkalosis, sodium regularly tended to shift into the cells and potassium tended to leave them. In most instances the reverse occurred during administration of ammonium chloride or hydrochloric acid. These shifts are barely significant numerically, but the uniformity of their direction suggests that some such redistribution is taking place. The meaning of such shifts is not clear but they may

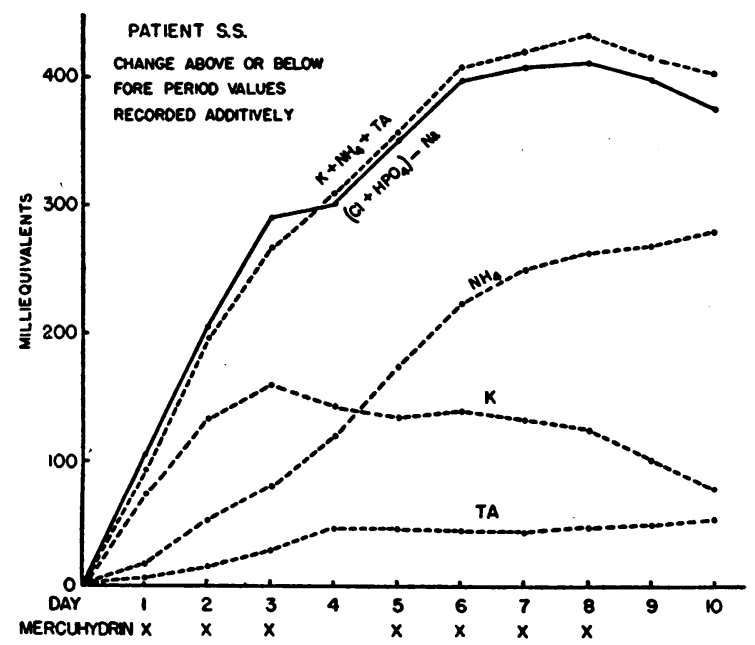

Fig. 6. Cumulative Urinary Excretions above Forraperiod Excretions for Patient S. S. (Table V) Plotted to Indicate the Quantities of Potassium and Ammontum Covering the Surplus of Chloride above Sodium during the Successive Days of the Diuresis serve the purpose of limiting the degree of relative acidosis or alkalosis in the extracellular fluid (3).

Figure 4 and Table V (S. S.) depict the course of the balance study in a patient who also responded with a loss of chloride in excess of sodium but who despite progressive alkalosis did not become refractory. The changes in the serum concentrations are similar to those occurring in patients F. C. and N. B. (see Figures 2 and 3 ). Administration of ammonium chloride on the sixth day resulted in a partial return toward normal of the serum values, as well as remission in the symptoms of lethargy and anorexia which had appeared as diuresis proceeded. During the initial diuresis approximately $5 \%$ of the estimated body potassium was lost in the urine. During the second diuretic period no loss of potassium occurred that could not be accounted for in the extracellular fluid which had been lost. Alkalosis continued to increase without loss of potassium as diuresis proceeded.

Although the signs of congestive failure were rapidly diminishing as diuresis continued, the patient became anorexic and lethargic once again and gradually lapsed into coma during the final two days of observation. Several hours before death, intermittent ventricular tachycardia and shock developed. The patient died on the 13th hospital day with no evidence of congestive failure other than mild peripheral edema. Postmortem examination did not provide an explanation of the death. It seems possible that the fatal outcome may have been related to the severe imbalance in the composition of the body fluid. Although $5 \%$ of the estimated body potassium had been lost in excess of nitrogen and there was an abnormally low serum concentration of potassium, there were no distinct clinical evidences of potassium deficiency and the electrocardiogram did not show signs of hypokalemia. Another factor contributing to the terminal shock-like state in this patient may have been the rapid and severe depletion of the body fluid volume. In the end phases of observation water retention appeared with a progressive decrease in the concentration of serum sodium. Although clinical deterioration was observed in this patient and in one other patient with alkalosis ( $\mathrm{J}$. C.) several patients, not included in the present data, have been observed to have values for se- 
rum $\mathrm{pH}$ of from 7.55 to 7.57 and total carbon dioxide concentrations of from 50 to $60 \mathrm{mEq} . / 1$. without the development of untoward symptoms and signs (15).

In Figure 5 a graphic analysis of the factors of anion-cation excretion in the urine of subject S. S. is presented. In the upper half of the chart the daily volumes and measurements of $\mathrm{pH}$ are shown. In the lower section the uppermost line records the daily fixed cation excretion plus urine ammonium and titratable acidity. Although the two relatively small components of fixed cation outgo in the urine, calcium and magnesium, are not included, sodium plus potassium plus ammonium plus titratable acid may be taken as approximately measuring the total cation excretion. By reference to the top line the anion excess over sodium plus potassium which is covered by ammonium plus titratable acid is defined. The relatively very small value for the unmeasured anions, phosphate, sulfate and organic acids, is shown by the proximity of the chloride measurements to this line.

In both periods of administration of Mercuhydrin urine volume is seen to increase greatly on the first day and then decline progressively, although a quite large diuretic effect continued to be obtained, and there was roughly corresponding change in the outgo of chloride and sodium in the urine. In the first period as may be seen by reference to the values before diuresis (days 1 and 2) removal of potassium was extensively increased whereas in the second period urine potassium was not above the initial value. This is explained by the larger values for ammonium and titratable acid over the second period.

The relation of potassium removal, ammonium production and urine acidity to the huge excess of chloride over sodium in the urine, which is the outstanding feature of the situation, is shown again in Figure 6. In this figure the daily values for change above or below the foreperiod measurements are recorded additively. The solid line defines, on this basis, anion excess composed of chloride plus phosphate over sodium. Measurements of sulfate and organic acids were not obtained. There was, as shown by the measurements in Table $\mathrm{V}$, an increase of urine phosphate during the first mercuhydrin period along with the increased removal of potassium. The values for potassium, ammonium and titratable acid are re- corded separately. Taken together, as shown by the uppermost broken line, they quite closely follow the anion excess over the sodium. The large removal of potassium above the foreperiod level during the first period of diuresis is quite clearly referable to the lag in ammonium production with the result that intracellular fixed cation is required to complete the coverage of anion excess over sodium. After the third day the increase of ammonium plus titratable acid permits the excretion of potassium to fall below the foreperiod value and there is gradual recovery of the potassium lost over the first three days. It should be noted that in some patients the discrepancy between chloride and sodium may be made up entirely by potassium without significant change in excretion of ammonium or titratable acid during the period of diuresis. This is illustrated particularly well in the data shown in Table IV (N. B.).

\section{DISCUSSION}

By means of direct observations on the kidney and short-term clearance studies investigators have identified many of the renal effects of mercurial compounds. The diuretic action of these drugs may be accounted for by a direct renal action (16, 17). Diuresis after single doses of mercurial compounds is not associated with an increase in the renal blood flow or in glomerular filtration rate but is apparently the result of a decreased tubular reabsorption of certain electrolytes $(18-20)$. It is not clear whether the depression of reabsorption occurs in the proximal or in the distal tubule. Conclusions on this point have differed, depending on the conditions under which observations were made $(21,22)$. In addition to the effects on reabsorption, mercurial compounds affect tubular secretory function. In man, tubular secretion of para-amino-hippurate is diminished (23); in the dog, tubular secretion of potassium is inhibited during potassium loading (24). A specific action of mercurial compounds on tubular reabsorption of water has not been described. Administration of free sulfhydryl groups in compounds such as 2,3 dimercaptopropanol (British Anti-Lewisite) will inhibit mercurial diuresis (25-27).

The results in the present studies, as well as those of Blumgart and associates $(1,19)$ in normal subjects and patients with congestive heart failure may be interpreted to indicate that mercury 
specifically depresses the tubular reabsorption of chloride and that cation excretion follows passively. The quantity of body fluid removed, however, is more closely related to fixed cation removal than to anion removal. In each period of diuresis the loss of sodium plus potassium is nearly equal to that predicted from the weight loss and concentration of these ions in the body fluids.

In a minority of the patients the explanation that sodium excretion is secondary to chloride excretion apparently does not account for the findings during diuresis. In these, sodium and chloride were lost in the proportion found in extracellular fluid. It should also be noted that, even in the patients who lost more chloride than sodium, the ratio of these losses varied widely. The factors responsible for the variation are not clear and require further study before a generally applicable concept describing the action of mercurial diuretics can be stated. It is possible that in every instance the effect of mercury is primarily on the reabsorption of chloride and that under optimal circumstances sodium will be lost with chloride in proportions appropriate to the maintenance of normal body fluid composition. However, if the stimuli that lead to sodium retention are intense because of hormonal factors or disturbances in renal hemodynamics, or both, then the factors that control normal cation-anion balance might become secondary to the demands of sodium retention, and chloride would be lost in excess of sodium. It has recently been suggested that changes in plasma volume may exert controlling effects on the excretion of salt and water (28). According to this view, a decrease in plasma volume leads to retention of sodium and water. In some of the present group of patients, the intensity of the sodium-retaining response may, in part, have resulted from a decrease in plasma volume consequent upon the initial diuretic response to the mercurial. Under these circumstances, the rate at which interstitial fluid is withdrawn into the vascular compartment would play an important role in determining the $\mathrm{Na} / \mathrm{Cl}$ loss.

The tentative hypothesis that mercurial diuretics have their primary action on the tubular reabsorption of chloride is inferred from the observations presented here which indicate that, over the course of days, mercurials lead to a disproportionate removal of chloride from the body fluids. Other workers have suggested that the action of mercury may be primarily on proximal (22) or distal (21) tubular reabsorption of sodium. Such hypotheses find neither support nor refutation in the present data and their final evaluation must await further investigation.

Whatever the mechanism may ultimately prove to be, the data presented here indicate a close temporal relationship between the fall in serum chloride and rise in serum bicarbonate concentrations and the development of unresponsiveness to the mercurial. Repair of the chloride deficit and the concomitant alkalosis has regularly been accompanied by the return of responsiveness.

Although the evidence presented here suggests that in the unresponsiveness to mercurial diuretics the electrolyte disturbance is of critical importance, data of others suggest that the essential factor may be a reduction in glomerular filtration (21, 29). It is possible that reductions in glomerular filtration rate and serum chloride concentrations both produce unresponsiveness by diminishing the rate at which chloride is delivered to the tubules.

In the two patients whose losses during diuresis were of the same composition as extracellular fluid, responsiveness continued until edema had disappeared. One of them initially demonstrated hypochloremia and an elevated bicarbonate concentration of a degree often found in the refractory group. These abnormalities in this patient persisted throughout the period of study, suggesting that unresponsiveness may be more related to changes in concentration than to absolute levels. In this minority group of responsive patients no significant changes occurred in the rate of excretion of ammonium, potassium, or titratable acid.

In those patients who excreted chloride in excess of sodium during diuresis, the need for additional cation was met by the loss of potassium and ammonium in reciprocally variable quantities, and in some instances indirectly by an increase in the excretion of titratable acid. In many patients large amounts of titratable acid and ammonium continued to be excreted in the urine during the progression of the alkalosis. The production of an acid urine in the presence of alkalosis has previously been observed in conditions characterized by dehydration and sodium depletion and has been considered to represent urgent need for cation conservation by 
the body $(30,31)$. During the production of experimental potassium deficit in animals metabolic alkalosis develops (32). One explanation of this event could be the loss of acid in the urine, as is suggested by the observations made during presumed potassium deficit in man by Kennedy, Winkley, and Dunning (33) and by Broch (34). Other mechanisms that might account for the production of alkalosis are $(a)$ the exchange of hydrogen and potassium ions between extra- and intracellular fluid, or $(b)$ a loss from the intracellular space of potassium and the anion of some weak acid. That one of the latter two mechanisms may be operative is suggested by the data describing the course of patient N. B. (Table IV). Elevation of serum $\mathrm{pH}$ and a progressive rise in serum bicarbonate accompanied by a fall in serum chloride concentration occurred without an appreciable increase in the excretion of ammonia or titratable acid. The urine remained close to neutrality as the chloride lost in excess of sodium was excreted with an almost equivalent amount of potassium. The observation that the intracellular $\mathrm{pH}$ of muscle tends to fall during imposed alkalosis likewise supports the possibility of internal transfers (35).

The loss of potassium finds its most ready explanation in the discrepancy between the excretion of sodium and chloride. In certain patients, as has been shown, potassium appears to act as a temporary source of cation until ammonium production is sufficiently increased to conserve fixed cation. In other patients potassium continues to furnish a large portion of the cation throughout the period of diuresis.

Two other possible mechanisms suggest themselves as factors in the potassium loss, though neither of these explains the data in all instances. Depression of the tubular reabsorption of potassium by mercurials has been shown to occur in the dog (24). If this occurs in man the effect must be transitory or irregular since 24-hour periods of observation in the present group of patients often indicated no loss of potassium. A third explanation, as suggested by the work of Darrow and associates (32), might be that the loss of potassium is the result of a biological equilibrium attained when normal renal function is carried out in the presence of deficit of certain ions in the body fluids. However, in the present group of patients, renal function cannot be considered normal and the defi- cits of potassium either did not occur or were of a much smaller degree than those demonstrated by these authors.

It should be pointed out that, even when there is a loss of potassium in excess of nitrogen, the deficits rarely appeared to be of clinical significance. Electrocardiograms were obtained on all patients during successive phases of the observations and were at no time suggestive of potassium deficit. Except for one instance, as long as the intake of food was adequate, the deficits of potassium were quickly repaired when mercurial administration was stopped. The possibility remains, however, that during a prolonged period of diuresis, a patient may become potassium deficient, particularly if his intake of food is low.

It has long been known that acidifying salts potentiate, and alkalinizing salts depress mercurial diuresis $(2,36,37)$. The potentiation with acidifying salts has been found to be synergistic rather than additive. Recent studies in dogs by Axelrod and associates suggest that a change in $\mathrm{pH}$ is not the leading factor (38). Reduction in $\mathrm{pH}$ by the administration of ammonium chloride is followed by a synergistically potentiated response to mercurials but a comparable reduction in $\mathrm{pH}$ induced by breathing $7 \%$ carbon dioxide does not enhance the diuretic effect (38). It would appear from the present data that it is the anion pattern of the serum that is important in determining the diuretic response. That acidifying salts containing anions other than chloride potentiate diuresis may be explained by postulating that these anions either (1) substitute for chloride, or (2) allow for an increase in the concentration of chloride in the body fluids. Evidence for the second viewpoint is provided by the studies of Gamble and associates (39). These authors have shown that the administration of ammonium sulfate leads to elevation of the serum chloride concentration. Review of their data indicates the explanation of this phenomenon is that the diuresis induced by sulfate leads to an obligatory removal of cation and water without proportional loss of chloride.

It should be noted that in the present group of patients the reduction in serum chloride concentration was in no instance accompanied by a fall in serum sodium concentration while diuresis was occurring. The occurrence of hypotonicity after mercurial diuresis has, however, been reported by 
many authors (40-42). The hypochloremic alkalosis seen in the present patients must be differentiated from the true "low salt" syndrome. Hypotonicity failed to develop in the present patients because water and cation were removed in proportional amounts. The development of hypotonicity requires the removal of cation without proportional quantities of water, the retention of water alone, or changes in the state of dissociation of certain intracellular compounds. Although hypertonic salt solution has been suggested for use in the management of hypotonicity associated with mercurial diuresis, there appeared to be no indication for its use in the group of patients here described.

\section{SUMMARY AND CONCLUSIONS}

The balance of weight, nitrogen, and electrolytes, the electrolyte changes in the serum, and the cation-anion pattern of the urine were studied in 10 patients with congestive heart failure who were undergoing mercurial diuresis.

The pattern of the balances was interpreted in terms of body composition and over-all function of the kidneys.

A minority of the patients lost water and electrolytes in a manner indicating that the only significant change in the body fluids was loss of extracellular fluid of usual composition. This small group of patients never developed mercurial unresponsiveness.

The majority of patients lost electrolytes and water in proportions that led to chloride depletion and alkalosis without change in the concentration of sodium in the serum. This type of response was often associated with a loss of intracellular fluid and potassium as well as with reduction of serum potassium concentration. In this group unresponsiveness to the diuretic developed in all but one instance. Repair of the chloride deficit with ammonium chloride or hydrochloric acid restored mercurial responsiveness. The serum concentrations of chloride and bicarbonate associated with unresponsiveness varied from patient to patient. In those patients in whom chloride excretion exceeded sodium excretion the surplus of chloride was covered by potassium and ammonium.

It has been suggested that the usual renal response to mercurial diuretics may result from interference with tubular reabsorption of chloride and that the loss of fixed cation is secondary to the effect on anion excretion. Possible factors determining the ratio of sodium to chloride loss have been discussed.

\section{ACKNOWLEDGMENTS}

The authors wish to express their appreciation to Dr. Samuel A. Levine for his advice and guidance in carrying out this study and to Dr. James L. Gamble for his contributions to the form of presentation and analysis of the data. They also wish to thank Miss Elizabeth Bradley and Mr. Joseph Greaney for their valuable technical assistance.

\section{REFERENCES-}

1. Blumgart, H. L., Gilligan, D. R., and Volk, M. C., Action of diuretic drugs. II. Effect of diuretic drugs on the acid-base equilibrium of the blood in patients with cardiac edema. Medical papers dedicated to Henry Asbury Christian. Waverly Press, Inc., Baltimore, 1936, p. 191.

2. Ethridge, C. B., Myers, D. B., and Fulton, M. N., The modifying effect of various inorganic salts on the diuretic action of salyrgan. Medical papers dedicated to Henry Asbury Christian. Waverly Press, Inc., Baltimore, 1936, p. 223.

3. Gamble, J. L., Wallace, W. M., Eliel, L., Holliday, M. A., Cushman, M., Appleton, J., Shenberg, A., and Piotti, J., Effects of large loads of electrolytes. Pediatrics, 1951, 7, 305.

4. Henderson, L. J., and Palmer, W. W., On the several factors of acid excretion. J. Biol. Chem., 1913-14, 17, 305.

5. Folin, O., Laboratory Manual of Biological Chemistry. Appleton-Century, New York, 1934, 5th ed., p. 141.

6. Lavietes, P. H., D'Esopo, L. M., and Harrison, H. E., The water and base balance of the body. J. Clin. Invest., 1935, 14, 251.

7. Darrow, D. C., da Silva, M. M., and Stevenson, S. S., Production of acidosis in premature infants by protein milk. J. Pediat., 1945, 27, 43.

8. Elkinton, J. R., Winkler, A. W., and Danowski, T. S., Inactive cell base and the measurement of changes in cell water. Yale J. Biol. \& Med., 1944, 17, 383.

9. Reifenstein, E. C., Jr., Albright, F., and Wells, S. L., The accumulation, interpretation, and presentation of data pertaining to metabolic balances, notably those of calcium, phosphorus, and nitrogen. J. Clin. Endocrinol., 1945, 5, 367.

10. Arn, K. D., and Reimer, A., Minimal sodium losses through the skin. J. Clin. Invest., 1950, 29, 1342.

11. Freyberg, R. H., and Grant, R. L., Loss of minerals through the skin of normal humans when sweating is avoided. J. Clin. Invest., 1937, 16, 729.

12. Shohl, A. T., Mineral Metabolism. Reinhold, New York, 1939 (American Chemical Society Monograph Series No. 82), p. 20. 
13. Yannet, H., and Darrow, D. C., The effect of depletion of extracellular electrolytes on the chemical composition of skeletal muscle, liver, and cardiac muscle. J. Biol. Chem., 1940, 134, 721.

14. Gamble, J. L., Companionship of Water and Electrolytes in the Organization of Body Fluids, Lane Medical Lectures. Stanford University Press, Stanford, California, 1950.

15. Relman, A. S., and Schwartz, W. B., Unpublished data.

16. Govaerts, $P$., Origine rénale ou tissulaire de la diurèse par un composé mercurial organique. Compt. rend. Soc. de biol., 1928, 99, 647.

17. Bartram, E. A., Experimental observations on the effect of various diuretics when injected directly into one renal artery of the dog. J. Clin. Invest., 1932, 11, 1197.

18. Walker, A. M., Schmidt, C. F., Elsom, K. A., and Johnston, C. G., Renal blood flow of unanesthetized rabbits and dogs in diuresis and antidiuresis. Am. J. Physiol., 1937, 118, 95.

19. Blumgart, H. L., Gilligan, D. R., Levy, R. C., Brown, M. G., and Volk, M. C., Action of diuretic drugs; action of diuretics in normal persons. Arch. Int. Med., 1934, 54, 40.

20. Schmitz, H. L., Studies on the action of diuretics. I. The effect of euphyllin and salyrgan upon glomerular filtration and tubular reabsorption. J. Clin. Invest., 1932, 11, 1075.

21. Pitts, R. F., and Duggan, J. J., Studies on diuretics. II. The relationship between glomerular filtration rate, proximal tubular absorption of sodium and diuretic efficiency of mercurials. J. Clin. Invest., 1950, 29, 372.

22. Mudge, G. L., Foulks, J., and Gilman, A., Effect of urea diuresis on renal excretion of electrolytes. Am. J. Physiol., 1949, 158, 218.

23. Berliner, R. W., Kennedy, T. J., Jr., and Hilton, J. G., Salyrgan and renal tubular secretion of para-aminohippurate in the dog and man. Am. J. Physiol., 1948, 154, 537.

24. Mudge, G. H., Ames, A. III, Foulks, J., and Gilman, A., Effect of drugs on renal secretion of potassium in the dog. Am. J. Physiol., 1950, 161, 151.

25. Handley, C. A., and LaForge, M., Effect of thiols on mercurial diuresis. Proc. Soc. Exper. Biol. \& Med., 1947, 65, 74.

26. Farah, A., and Maresh, G., The influence of sulfhydryl compounds on diuresis and renal and cardiac circulatory changes caused by mersalyl. J. Pharmacol. \& Exper. Therap., 1948, $92,73$.
27. Earle, D. P., Jr., and Berliner, R. W., Effect of 2,3dimercaptopropanol on diuresis. Am. J. Physiol., 1947, 151, 215.

28. Peters, J. P., Sodium, water and edema. J. Mt. Sinai Hosp., 1950, 17, 159.

29. Weston, R. E., and Escher, D. J. W., An analysis of the unresponsiveness to mercurial diuretics observed in certain patients with severe chronic congestive failure. J. Clin. Invest., 1948, 27, 561.

30. Gamble, J. L., and Ross, S. G., The factors in the dehydration following pyloric obstruction. J. Clin. Invest., 1924, 1, 403.

31. Van Slyke, K. K., and Evans, E. I., The paradox of aciduria in the presence of alkalosis caused by hypochloremia. Ann. Surg., 1947, 126, 545.

32. Darrow, D. C., Schwartz, R., Iannucci, J. F., and Coville, F., The relation of serum bicarbonate concentration to muscle composition. J. Clin. Invest., 1948, 27, 198.

33. Kennedy, T. J., Jr., Winkley, J. H., and Dunning, M. F., Gastric alkalosis with hypokalemia. Am. J. Med., 1949, 6, 790.

34. Broch, O. J., Low potassium alkalosis with acid urine in ulcerative colitis. Scandinav. J. Clin. \& Lab. Invest., 1950, 2, 113.

35. Wallace, W. M., and Hastings, A. B., The distribution of the bicarbonate ion in mammalian muscle. J. Biol. Chem., 1942, 144, 637.

36. Keith, N. M., Whelan, M., and Bannick, E. G., The action and excretion of nitrates. Arch. Int. Med., 1930, 46, 797.

37. Lyons, R. H., Jacobson, S. D., and Avery, N. L., The change in plasma volume and body weight in normal subjects after a low-salt diet, ammonium chloride and mercupurin. Am. J. M. Sc., 1946, 211, 460.

38. Axelrod, D. R., Capps, J. N., and Pitts, R. F., Potentiation of diuretic action of salrygan by ammonium chloride. Federation Proc., 1950, 9, 6.

39. Gamble, J. L., Blackfan, K. D., and Hamilton, B., A study of the diuretic action of acid producing salts. J. Clin. Invest., 1924, 1, 359.

40. Soloff, L. A., and Zatuchni, J., Syndrome of salt depletion, induced by a regimen of sodium restriction and sodium diuresis. J. A. M. A., 1949, 139, 1136.

41. Schroeder, H. A., Renal failure associated with low extracellular sodium chloride; the low salt syndrome. J. A. M. A., 1949, $141,117$.

42. Citron, D., Bercu, B., Lemmer, R., and Massie, E., Congestive heart failure and hyponatremia: untoward effects of mercurial diuresis. Ann. Int. Med., 1951, 34, 872. 